\title{
External beam radiation therapy in treatment of malignant pheochromocytoma and paraganglioma
}

\author{
Jennifer Vogel ${ }^{1 *}$, Aileen Sia Atanacio ${ }^{2}$, Tamara Prodanov ${ }^{2}$, Baris Ismail Turkbey $^{3}$, Karen Adams ${ }^{2}$, \\ Victoria Martucci ${ }^{2}$, Kevin Camphausen ${ }^{1}$, Antonio Tito Fojo ${ }^{4}$, Karel Pacak ${ }^{2}$ and Aradhana Kaushal $^{1}$ \\ ${ }^{1} \mathrm{NIH}$, Radiation Oncology Branch, National Cancer Institute, Bethesda, MD, USA \\ ${ }^{2} \mathrm{NIH}$, Program in Reproductive and Adult Endocrinology, Eunice Kennedy Shriver National Institutes of Child Health and Human Development, Bethesda, MD, USA \\ ${ }^{3} \mathrm{NIH}$, Molecular Imaging Program, National Cancer Institute, Bethesda, MD, USA \\ ${ }^{4} \mathrm{NIH}$, Medical Oncology Branch, National Cancer Institute, Bethesda, MD, USA
}

\author{
Edited by: \\ Anatoly Dritschilo, Georgetown \\ University School of Medicine, USA \\ Reviewed by: \\ Daniel Hamstra, University of \\ Michigan, USA \\ Sonali Rudra, MedStar Georgetown \\ University Hospital, USA \\ *Correspondence: \\ Jennifer Vogel, NIH, Radiation \\ Oncology Branch, Bethesda, MD \\ 20892, USA \\ e-mail: \\ jennifer.vogel@uphs.upenn.edu
}

\begin{abstract}
Purpose: Pheochromocytomas (PCCs) are neuroendocrine tumors arising from the adrenal medulla or as paraganglioma (PGL) from extra-adrenal sites. While usually benign, a small fraction is malignant. Multi-modality therapy is used in treating malignant disease; however, little data exist on the role of external beam radiation therapy (EBRT). In this retrospective review, we assessed response to EBRT in malignant PCCs or PGLs.
\end{abstract}

Methods and Materials: Records of patients treated at the National Institutes of Health who received EBRT between 1990 and 2012 were studied. Patients were assessed for symptomatic control, biochemical response, local and distant control by response evaluation criteria in solid tumors $v 1.1$ or stable disease on imaging reports, toxicity by radiation therapy oncology group (RTOG) criteria, and survival.

Results: There were 24 patients treated who received EBRT to lesions of the abdomen $(n=3)$, central nervous system $(n=4)$, and bone $(n=40)$. Lesions were treated with $3 \mathrm{D}$ conformal EBRT to a mean dose of $31.8 \mathrm{~Gy}$ in $3.3 \mathrm{~Gy}$ fractions, or fractionated stereotactic radiosurgery to $21.9 \mathrm{~Gy}$ in $13.6 \mathrm{~Gy}$ fractions. Patients experienced acute $(n=15)$ and late $(n=2)$ RTOG toxicities; no patient experienced acute toxicity $\geq 4$ or late toxicity $\geq 2$. Symptomatic control was achieved in $81.1 \%$ of lesions. Stable radiographic response was achieved in $86.7 \%$ of lesions with progression in $13 \%$. Distant progression was observed overall in $75 \%$ of patients and average survival was 52.4 months.

Conclusion: Malignant PCC and PGL often do not respond well to current systemic therapies. In these cases, EBRT can be considered in patients with symptomatic, localized disease progression.

Keywords: radiation, pheochromocytoma, paraganglioma, malignant, neuroendocrine

\section{INTRODUCTION}

Pheochromocytomas (PCCs) are neuroendocrine tumors arising from chromaffin cells of the adrenal medulla. Closely related tumors of the extra-adrenal paraganglia are termed as paragangliomas (PGLs). Adrenal PCCs are the most common chromaffin tumors, occurring in about $80-85 \%$ of cases. The remainder occur

Abbreviations: CgA, chromogranin A; CNS, central nervous system; CR, complete response; $\mathrm{CT}$, computed tomography; DP, distant progression; EBRT, external beam radiation therapy; FSRT, fractionated stereotactic radiosurgery; IMRT, intensity modulated radiation therapy; $\mathrm{LD}$, local disease; LP, local progression; $\mathrm{MRI}$, magnetic resonance imaging; NFI, neurofibromatosis type 1; PMN, plasma metanephrine; PCC, pheochromocytoma; PD, progressive disease; PGL, paraganglioma; PGL1, familial paraganglioma syndrome type 1; PGL2, familial paraganglioma syndrome type 2; PGL4, familial paraganglioma syndrome type 4; RECIST, response evaluation criteria in solid tumors; RET, group rearranged during transfection; RTOG, radiation therapy oncology; $\mathrm{SD}$, stable disease; $\mathrm{SDHB}$, succinate dehydrogenase subunit B; SDHC, succinate dehydrogenase subunit C; SDHD, succinate dehydrogenase subunit D; SRS, stereotactic radiosurgery; TTP, time to progression; UMN, urinary metanephrine; VHL, von Hippel-Lindau. as PGLs, which may be classified as branchiomeric, including glomus jugulare and carotid body tumors; intravagal; aorticosympathetic; and visceral-autonomic. These tumors are rare, with an annual reported incidence of two to eight per million population and prevalence in $0.2-0.4 \%$ of hypertensive patients. They are characterized by their ability to synthesize, store, and secrete catecholamines although some, especially those of branchiomeric or intravagal origin, are non-functional. Elevated urinary fractionated and plasma free metanephrines have been shown to be sensitive markers of disease and are therefore often used in diagnosis. Although less sensitive for diagnosis, chromogranin A levels are also valuable in following response to therapy and monitoring for recurrence (1).

While most occur as sporadic tumors, about $30-35 \%$ is associated with hereditary syndromes. These include multiple endocrine neoplasia type 2 arising from mutations in the rearranged during transfection $(R E T)$ proto-oncogene; von Hippel-Lindau (VHL) syndrome caused by mutations of the VHL gene; and von Recklinghausen's disease due to mutations of the 
Table 1 | Malignant PCC/PGL cases treated to known total dose

\begin{tabular}{|c|c|c|c|c|}
\hline Reference & $N$ & Site & Dose (Gy) & Results \\
\hline Fishbein et al. (11) & 17 & Malignant PCC/PGL outside the head and neck & Median 40 & $\begin{array}{l}76 \% \text { local control or significant symptomatic } \\
\text { relief }\end{array}$ \\
\hline Pham et al. (10) & 7 & Bony metastasis (5) and abdominal primary (2) & Mean $44 \pm 0.04$ & $71 \%$ effective in relieving pain $(5 / 7)$ \\
\hline Yoshida et al. (12) & 3 & Pelvic, para-aortic, left inguinal lymph nodes & Median 55 & $\begin{array}{l}\text { Control of catecholamines, hypertension, and } \\
\text { swelling }\end{array}$ \\
\hline Elder et al. (13) & 4 & Osseous metastases & Median 20 & $\begin{array}{l}100 \% \text { with decreased urine catecholamines and } \\
\text { temporary alleviation in pain }\end{array}$ \\
\hline Teno et al. (14) & 2 & Sacral and vertebral metastases & Mean 30 & $\begin{array}{l}\text { No significant change, exacerbated } \\
\text { hypertension }\end{array}$ \\
\hline Brodkey (15) & 2 & Vertebral metastasis & Mean 47 & Resolution of myelopathy \\
\hline Hamilton (16) & 4 & Bony metastasis & Median 40 & $\begin{array}{l}\text { Symptomatic improvement }(50 \%) \text {; distant } \\
\text { progression (100\%) }\end{array}$ \\
\hline Jindel (17) & 2 & Bony metastasis & Mean 38.7 & Resolution of myelopathy and swelling \\
\hline Yu (18) & 3 & Various & Median 25 & $\begin{array}{l}\text { Higher doses may have resulted in sustained } \\
\text { remission }\end{array}$ \\
\hline Olson (19) & 2 & Bony metastasis & Mean 30 & $\begin{array}{l}\text { Resolution of pain and weakness; distant } \\
\text { progression }\end{array}$ \\
\hline Siddiqui (20) & 3 & Abdominal primary, femur, spinal cord & Median 25 & $\begin{array}{l}\text { Resolution of pain and neurologic symptoms; } \\
\text { distant progression }\end{array}$ \\
\hline Drasin (7) & 2 & Vertebral metastasis & Mean 36.5 & Resolution of pain, slowed progression \\
\hline James et al. (21) & 10 & Various & Median 25 & $\begin{array}{l}50 \% \text { treated with }<2500 \text { Gy without } \\
\text { symptomatic or survival benefit }\end{array}$ \\
\hline Scott (8) & 15 & Various & Median 32.5 & $\begin{array}{l}\text { Some control of pain and BP, complicated by } \\
\text { leukopenia }\end{array}$ \\
\hline Holsti (22) & 6 & Various & Median 44.5 & $66 \%$ survival at 2 years \\
\hline Moloney (9) & 6 & Various & Median 30.75 & $\begin{array}{l}\text { Pain control at bony metastasis; poorly tolerated } \\
\text { at primary }\end{array}$ \\
\hline
\end{tabular}

neurofibromatosis type 1 (NF1) gene. In addition, mutations in genes encoding succinate dehydrogenase subunits ( $S D H D, S D H C$, and $S D H B$ ) are associated with familial PGL syndromes (PGL1, PGL3, and PGL4), respectively.

Currently, the only diagnostic criterion for malignant disease is the presence of metastasis. The proposed incidence of malignant disease ranges from 3 to $36 \%$ with generally lower rates of malignancy in PCC compared to PGL. However, rates of malignancy have been reported as high as $50 \%$ in patients with $S D H B$ mutation. Overall 5-year survival in the setting of benign disease is between 90 and 95\%. Prognosis of malignant PCC and PGL is poor, with a 5 -year survival between 34 and $72 \%$. While benign disease can generally be definitively treated with surgical resection, malignant PCC and PGL currently have no cure. Patients are treated with multi-modality therapy, which may include surgical resection, radiopharmaceutical therapy, chemotherapy, and radiofrequency ablation. Within these treatment options for malignant disease, the role of external beam radiation therapy (ERBT) remains largely undefined.

Ascribing a role to EBRT in the treatment of malignant PCC/PGL is difficult given limited numbers of patients and reports in the literature. There have been case reports on malignant PCC/PGL in which EBRT was delivered to unknown total doses. In these cases, irradiation was delivered to the primary tumor or metastatic sites with varying symptomatic control and most often with progression of local and distant disease (2-6). However, these reports may be of limited utility especially in PCC/PGL, given results from a 1978 literature review, which concluded that radiation therapy is beneficial for symptomatic relief of bone and lymph node metastases only at high doses (7).

Use of high-dose EBRT outside of bone and lymph node metastases was associated with significant normal tissue toxicity in older case reports, limiting its utilization for malignant PCC/PGL $(8,9)$. More recent case reports in which intensity 


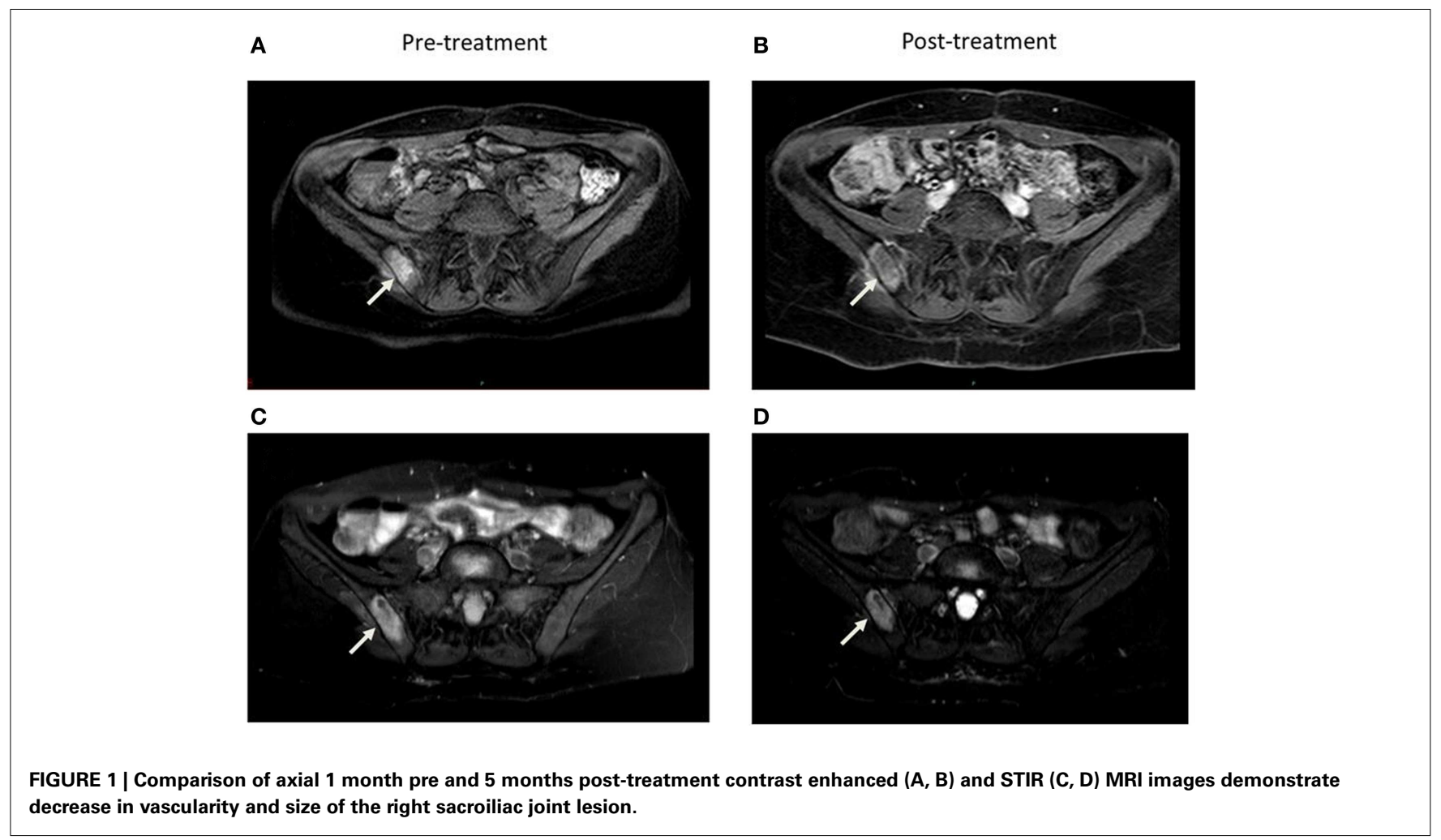

modulated radiation therapy (IMRT) or stereotactic radiosurgery and fractionated stereotactic radiosurgery (SRS/FSRT) are used, however, have allowed delivery of higher doses of radiation without significant normal tissue toxicity, resulting in durable local radiographic and symptomatic control at broader sites of metastatic disease (10). However, all of these reports are based on limited numbers of patients and lesions with the exception of a recent study on the role of EBRT and ${ }^{131}$ I-MIBG in non-head-and-neck PCC or PGL (11) (Table 1). In addition, this is the only study utilizing radiographic and biochemical responses to measure outcomes following EBRT in a subset of the patients reviewed. In the majority of case reports, patient characteristics as well as radiation techniques and outcomes are incompletely documented and direct comparison of the patients across these reports is difficult.

The objective of this study was to better characterize the utility of EBRT within multi-modality therapy by performing a retrospective review analyzing symptomatic, radiographic, and biological responses to treatment of patients with malignant PCC or PGL.

\section{MATERIALS AND METHODS}

A retrospective chart review of endocrinology patients treated at the National Institutes of Health between 1990 and 2012 was performed. Patients were selected if they received EBRT for pathologically confirmed malignant PCC/PGL. Irradiation was performed using either ${ }^{60} \mathrm{Co}$ machine or 4 - to $23-\mathrm{MV}$ photons from a linear accelerator. Patient charts were assessed for: age, sex, familial syndromes, pre-treatment and post-treatment plasma and urinary metanephrine (PMNs, UMNs), and chromogranin A (CgA) levels within 5-6 months of radiation therapy, total radiation dose and fraction size, radiation technique, symptomatic response, local and distant radiographic response or control, radiation toxicities, additional therapies after treatment, and survival time.

Radiographic response was determined by response evaluation criteria in solid tumors (RECIST) v1.1 based on computed tomography (CT) or magnetic resonance imaging (MRI) reports for a subset of eight patients with 12 lesions with pre and posttreatment imaging available for evaluation (Figure 1). The criteria were applied to these patients for both local and distant, or nontarget, disease. For the remainder of patients without imaging available, local and distant control was defined as stable lesion size and progression defined as any increase in size or number as documented by imaging reports. Given the retrospective nature of this study, imaging was performed at variable intervals based on physician discretion. Local and distant control was determined at the time of last available post-treatment imaging. Time to progression (TTP) was defined in months beginning on the first day of EBRT to first progression of local or distant disease in both subsets of patients. Toxicity was graded according to the radiation therapy oncology group (RTOG) acute and late criteria extrapolated from documentation in charts and on-treatment notes. Survival time was defined as months from ERBT to death or to last follow-up.

\section{RESULTS}

Treatment courses for 24 patients with a total of 47 lesions who met these criteria were reviewed. Patients were an average age of 34.1 years at diagnosis (range 12-59 years). Eight patients presented with metastases and 16 recurred with metastases an average of 6.2 years (2-264 months) after resection of the primary tumor. 
Table 2 | Patient characteristics

Characteristic

\begin{tabular}{|c|c|}
\hline \multicolumn{2}{|l|}{ AGE AT DIAGNOSIS } \\
\hline Average & 39.5 \\
\hline Range & $12-59$ \\
\hline \multicolumn{2}{|l|}{ SEX } \\
\hline Male & $14(58 \%)$ \\
\hline Female & $10(42 \%)$ \\
\hline \multicolumn{2}{|l|}{ PRESENTATION } \\
\hline Metastatic disease & $8(33 \%)$ \\
\hline Local disease & $16(67 \%)$ \\
\hline Average time to metastasis & 6.2 years \\
\hline \multicolumn{2}{|l|}{ MUTATION STATUS } \\
\hline SDHB & $9(38 \%)$ \\
\hline SDHD & $1(4 \%)$ \\
\hline RET & $1(4 \%)$ \\
\hline \multicolumn{2}{|l|}{ THERAPY PRIOR TO EBRT } \\
\hline CVD & $4(17 \%)$ \\
\hline Resection & $22(92 \%)$ \\
\hline RFA & $2(8 \%)$ \\
\hline \multicolumn{2}{|l|}{ INDICATION FOR RT } \\
\hline Pain & $32(68 \%)$ \\
\hline Cord compression & $2(4 \%)$ \\
\hline Tinnitus/hearing loss & $2(4 \%)$ \\
\hline Double vision & $1(2 \%)$ \\
\hline Residual disease & $10(21 \%)$ \\
\hline \multicolumn{2}{|l|}{ SITETREATED } \\
\hline Bony metastases & $40(85 \%)$ \\
\hline Abdominal tumor & $3(6 \%)$ \\
\hline CNS & $4(9 \%)$ \\
\hline
\end{tabular}

One patient had a RET mutation, one had $S D H D$ mutation, and nine had SDHB mutations. Prior to EBRT, 16 patients underwent surgical resection alone; 3 received resection followed by systemic chemotherapy (CVD, 3-26 cycles); 1 underwent resection with RFA to liver metastases; 1 underwent resection with systemic yttrium-90 therapy; and 1 underwent resection, systemic chemotherapy (CVD, 2 cycles), and RFA to iliac crest lesions. Only two patients received biopsy alone prior to EBRT (Table 2).

Patients received EBRT to abdominal, CNS, and bone lesions. Bone lesions were treated with 3D conformal EBRT to a mean dose of $32.6 \mathrm{~Gy}$ in $3.9 \mathrm{~Gy}$ fractions, CNS tumors to a mean of $30.3 \mathrm{~Gy}$ in $2.1 \mathrm{~Gy}$ fractions, and abdominal disease to a mean of $54 \mathrm{~Gy}$ in $1.8 \mathrm{~Gy}$ fractions. The overall mean was $31.8 \mathrm{~Gy}$ in $3.3 \mathrm{~Gy}$ fractions. Treatments were delivered by SRS to a single bony lesion to $24 \mathrm{~Gy}$; by SRS to a CNS lesion at a dose of $14 \mathrm{~Gy}$; and by FSRT to two abdominal masses to 24.0 and $25.5 \mathrm{~Gy}$ in 8.0 and $8.5 \mathrm{~Gy}$ fractions, respectively. Of the 47 sites treated, 37 were symptomatic. Of lesions which were symptomatic, improvement in symptoms was reported in $81.1 \%(n=30)$, with response of two symptomatic lesions included in analysis lost to follow-up.

Following RT, 13 patients received systemic chemotherapy for an average of 8.7 cycles (CVD; cytoxan and adriamycin; temozolomide; MS275, 6-18 cycles). Patients were treated with radiopharmaceutical therapy: nine were treated with ${ }^{131}$ I-MIBG therapy, one received radioactive octreotide, and one received radioactive Yttrium-90. Patients received additional surgery $(n=8)$ and RFA $(n=2)$. Only three patients died from progressive disease (PD) and mean follow-up time was 52.4 months.

For lesions evaluated by RECIST response, stable disease (SD) was achieved in $83.3 \%$ and PD in $16.7 \%(n=2)$ with an average TTP of 22.47 months. For non-target disease, $28.6 \%$ of patients $(n=2)$ achieved complete response (CR), $14.2 \%$ had non$\mathrm{PR} /$ non-CR $(n=1)$, and $71.4 \%$ had PD with an average TTP of 13 months. Of the lesions not evaluable by RECIST, local control was achieved in $82.8 \%$ of lesions, with $11.4 \%$ progressing $(n=4)$ at an average of 14.8 months. For non-target disease, $16.7 \%$ of patients had no distant disease progression while $83.3 \%$ progressed at an average of 17.6 months. Overall, local control was observed in $86.7 \%$ of patients and progression in $13.3 \%$; distant control observed in $25 \%$ of patients and progression in $75 \%$ (Table 3 ).

Of patients with familial syndromes $(n=11), 78.5 \%$ of symptomatic lesions improved following radiation therapy. Patients with familial syndromes evaluated by RECIST criteria had $84.6 \%$ local SD with $15.3 \%$ local PD $(n=2)$ at an average of 13.43 months TTP. They had $92.3 \%$ distant PD with 7.6\% distant SD and an average TTP of 25.85 months. Of those not evaluated by RECIST criteria, $75 \%$ had local control and $25 \%(n=1)$ local progression at 28.63 months TTP. Distant CR was achieved in $33.3 \%(n=1)$ and distant progression occurred in $66.7 \%$ with an average TTP of 42.7 months.

Patients who received 3D conformal or IMRT responded best symptomatically at a higher average dose of $33.7 \mathrm{~Gy}$ while average dose for patients without improvement was $31.7 \mathrm{~Gy}(P=0.39)$. Local SD was achieved at an average of $34.75 \mathrm{~Gy}$ compared to 31 Gy for those with PD $(P=0.15)$. Progressive distant disease was observed at an average dose of $33.3 \mathrm{~Gy}$ with stable distant disease observed at an average of $36.0 \mathrm{~Gy}(P=0.34)$. In our study, $100 \%$ of patients treated with SRS/FSRT achieved local control $(n=4)$ compared to $85.3 \%(n=35)$ of those treated with standard fractionation.

All 24 patients were evaluated for biochemical response by chromogranin A, free plasma metanephrines, and fractionated urine metanephrines. Six patients had chromogranin A levels before and after radiation; four of these showed a positive biochemical response. Six patients had free plasma metanephrine levels, three with a decrease after radiation. Four patients had fractionated urine metanephrine levels, three with a decrease in value after radiation therapy (Table 4).

Toxicities from treatment were both acute and late. Patients experienced RTOG grade 1 acute skin $(n=3)$, esophageal $(n=4)$, and upper gastrointestinal $(n=2)$ toxicity, as well as grade 2 upper gastrointestinal $(n=4)$, and grade 3 upper gastrointestinal $(n=1)$ and esophageal $(n=1)$ toxicities. There were two reported late toxicities, one esophageal which subsequently resolved and one spinal cord which was permanent in one patient treated by SRS to C3 to 2400 cGy. No patient suffered RTOG acute toxicity grade $\geq 4$ or any RTOG late toxicity grade $\geq 2$.

\section{DISCUSSION}

In this retrospective analysis, we evaluated patients with malignant PCC/PGL with primary lesions in the head, neck, and abdomen. 
Table 3 | Results of EBRT therapy.

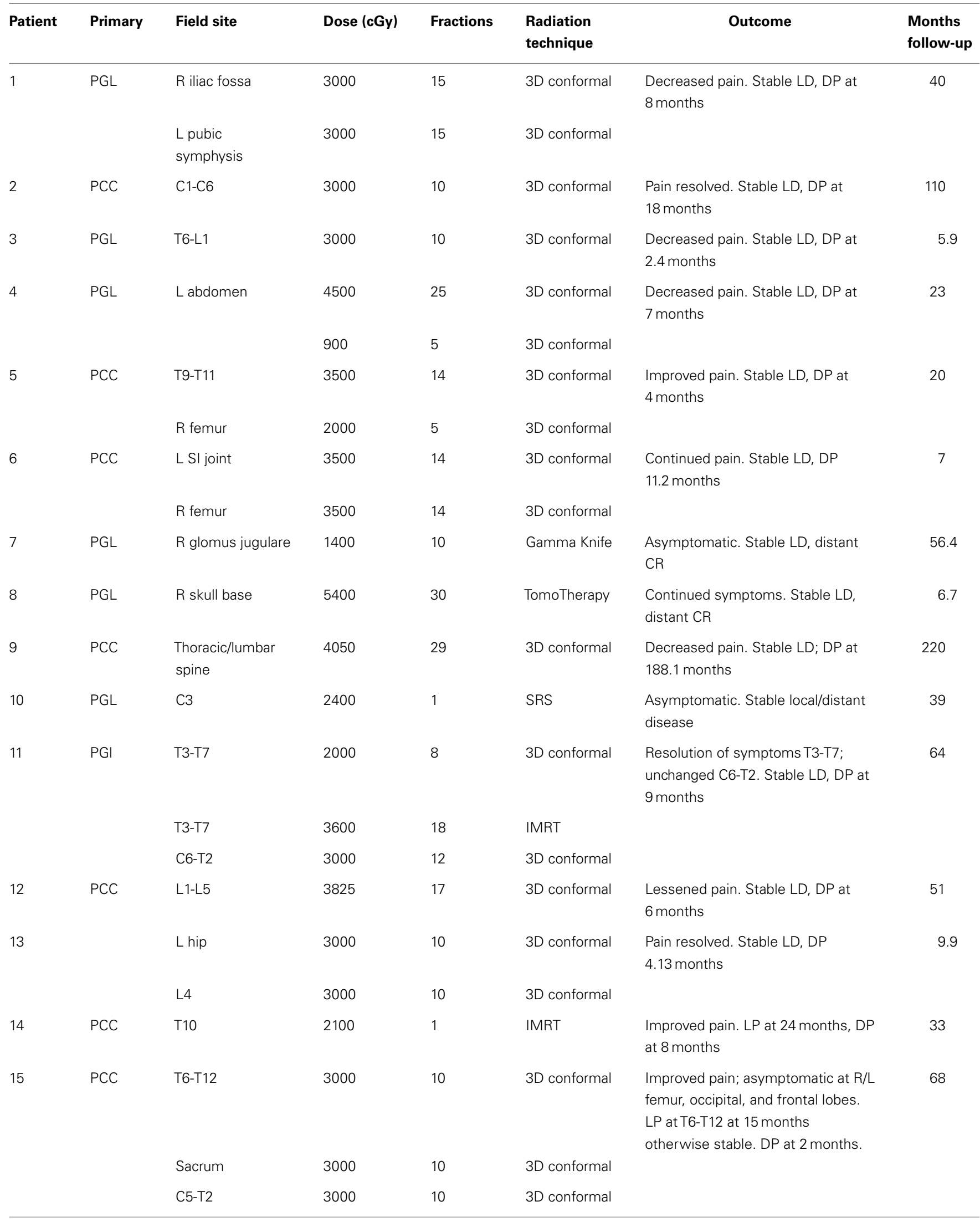


Table 3 | Continued

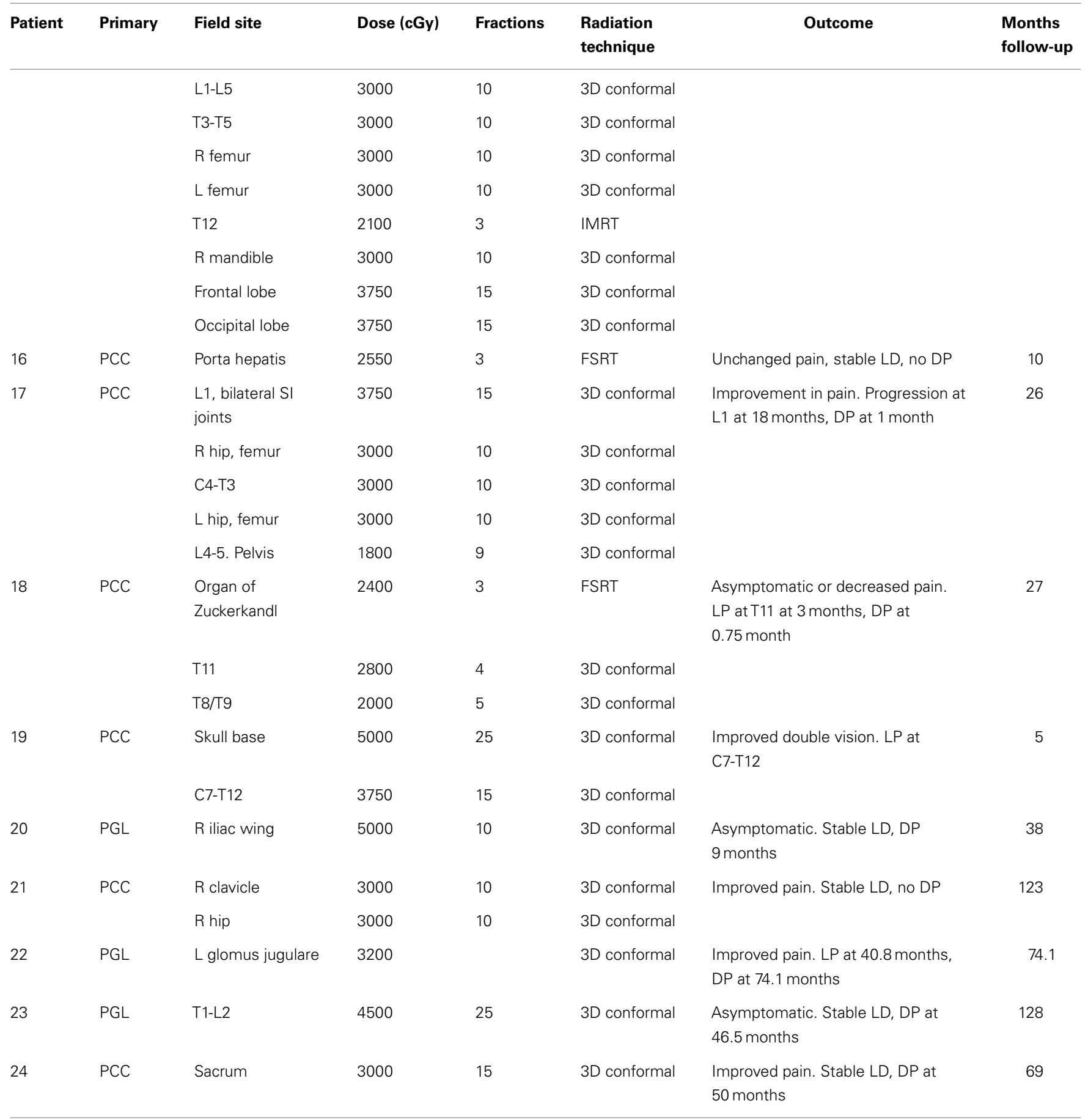

Our patients had metastatic lesions to bones, to the abdomen, and to the CNS. This series is the largest on the response of PCC/PGL to EBRT and, unlike many previous case series and case reports, utilizes newer technologies of 3D conformal radiation therapy including IMRT as well as SRS/FSRT. In addition, a subset of our patients was evaluated using standardized radiographic criteria and assessed for biochemical responses to localized radiation therapy. We found an overall symptomatic improvement in $81.1 \%$ of patients after radiation therapy regardless of site or radiation technique, with overall local control of $86.7 \%$ in patients treated to mean doses of $31.8 \mathrm{~Gy}$ in $3.3 \mathrm{~Gy}$ fractions by $3 \mathrm{D}$ conformal radiation therapy and $21.9 \mathrm{~Gy}$ in $10.4 \mathrm{~Gy}$ fractions by FSRT.

Our study shows a trend of greater symptomatic responses as well as local and distant control in patients who received higher 
Table 4 | Biochemical responses to EBRT.

\begin{tabular}{llcr}
\hline Patient & Biochemical test & $\begin{array}{c}\text { Pre-EBRT } \\
\text { measurement }\end{array}$ & $\begin{array}{c}\text { Post-EBRT } \\
\text { measurement }\end{array}$ \\
\hline 2 & PMN (nl: $12-61 \mathrm{pg} / \mathrm{mL})$ & 132 & 207 \\
6 & Chg A (nl: 0-225 ng/mL) & 296 & 257 \\
7 & Chg A (nl: 0-225 ng/mL) & 278 & 540 \\
& PMN (nl: $12-61 \mathrm{pg} / \mathrm{mL})$ & 32 & 36 \\
14 & Chg A (nl: 0-225 ng/mL) & 2160 & 1780 \\
& UMN (nl: $44-261 \mu \mathrm{g} / 24 \mathrm{~h})$ & 73 & 89 \\
19 & Chg A (nl: $0-225 \mathrm{ng} / \mathrm{mL})$ & 23,500 & 10,900 \\
& UMN (nl: $44-261 \mu \mathrm{g} / 24 \mathrm{~h})$ & 96 & 89 \\
\multirow{2}{*}{20} & PMN (nl: $12-61 \mathrm{pg} / \mathrm{mL})$ & 14 & 27 \\
& UMN (nl: $44-261 \mu \mathrm{g} / 24 \mathrm{~h})$ & 48 & 110 \\
22 & PMN (nl: $12-61 \mathrm{pg} / \mathrm{mL})$ & 25 & 23 \\
& Chg A (nl: $0-225 \mathrm{ng} / \mathrm{mL})$ & 93 & 84 \\
& UMN (nl: $44-261 \mu \mathrm{g} / 24 \mathrm{~h})$ & 93 & 110 \\
23 & PMN (nl: $12-61 \mathrm{pg} / \mathrm{mL})$ & 51 & 18 \\
& Chg A (nl: $0-225 \mathrm{ng} / \mathrm{mL})$ & 65,000 & 137,000 \\
\hline
\end{tabular}

doses of radiation compared to those who received shorter courses of radiation, although statistical significance was not reached possibly limited by the size of our cohort. Given that these treatments were well tolerated, outcomes may have improved with even higher doses of radiation over $40 \mathrm{~Gy}$ as suggested in other series and case $(10,11,13)$.

In addition, our study shows that most patients will not experience radiographic regression of their disease. This is consistent both with studies of malignant PCC/PGL, but also with extensive literature on EBRT for benign PGL, which has suggested that this is due to the slow growing nature of these tumors (11). While no target lesion had CR/PR, the three non-target lesions, which had CR or non-CR/non-PR were surgically resected and did completely or partially resolve on imaging. Consistent with other studies, our results indicate that patients may experience long term local and symptomatic control of their disease without significant imaging changes.

It is also important to consider the site of disease being treated when evaluating dose given by EBRT. While many of our patients with bony metastasis responded well to an average dose of $32.6 \mathrm{~Gy}$, a single patient with a primary malignant glomus jugulare experienced PD by RECIST criteria when treated with $32 \mathrm{~Gy}$. Some studies have indicated that these patients may require doses $>60 \mathrm{~Gy}$ for durable local control (23).

Fewer of our patients were treated with SRS/FSRT and, of these, only one was symptomatic at presentation. As a newer treatment modality, there is less follow-up time for patients with benign PGL treated with SRS although it has shown promising efficacy in many studies. In our study, durable local control was achieved in a greater proportion of patients treated with SRS/FSRT as compared with standard fractionation, although the number treated using this modality was much smaller. It has been suggested, however, that SRS be restricted in use to smaller tumors $<3 \mathrm{~cm}$ with a more protracted course of radiation either as 3D conformal EBRT or FSRT for larger lesions (23).
Radiation therapy remains a local therapy, and the majority of patients in this study progressed systemically through their radiation treatments, reinforcing the need for concurrent systemic therapy to control distant metastasis. In spite of this, for patients who were able to be evaluated for biochemical responses after radiation there was a decrease in chromogranin A and catecholamine levels, suggesting a decreased overall disease burden after radiation therapy.

As with other reports on the use of EBRT in malignant PCC/PGL, this study is limited by its retrospective nature and the small number of patients treated. However, we have found both 3D conformal EBRT and SRS/FSRT to be effective in controlling symptoms and local progression in patients with both sporadic and familial malignant PCC/PGL. Patients achieved better responses at higher doses in general, although the optimal dose and radiation technique may vary depending on the site treated and size of the lesion. In addition to currently available systemic therapies, EBRT may play a significant role in the control of local disease for these patients.

\section{REFERENCES}

1. Bravo EL, Tagle R. Pheochromocytoma: state-of-the-art and future prospects. Endocr Rev (2003) 24:539-53. doi:10.1210/er.2002-0013

2. Sclafani MT, Arnold PM, Anderson KK. Metastatic adrenal pheochromocytoma to the thoracic spine. Coluna/Columna (2010) 9:343-6. doi:10.1590/S180818512010000300017

3. Kasliwal MK, Sharma MS, Vaishya S, Sharma BS. Metachronous pheochromocytoma metastasis to the upper dorsal spine-6-year survival. Spine J (2008) 8:845-8. doi:10.1016/j.spinee.2007.06.004

4. Kheir E, Pal D, Mohanlal P, Shivane A, Chakrabarty A, Timothy J. Cervical spine metastasis from adrenal pheochromocytoma. Acta Neurochir (2006) 148:1219-20. doi:10.1007/s00701-006-0892-4

5. Pickard JL, Ross G Jr, Silver D. Coexisting extraadrenal pheochromocytoma and renal artery stenosis: a case report and review of the pathophysiology. J Pediatr Surg (1995) 30:1613-5. doi:10.1016/0022-3468(95)90172-8

6. Ein SH, Pullerits J, Creighton R, Balfe JW. Pediatric pheochromocytoma. A $36-$ year review. Pediatr Surg Int (1997) 12:595-8. doi:10.1007/s003830050218

7. Drasin H. Treatment of malignant pheochromocytoma. West J Med (1978) 128:106-11.

8. Scott HW Jr, Reynolds V, Green N, Page D, Oates JA, Robertson D, et al. Clinical experience with malignant pheochromocytomas. Surg Gynecol Obstet (1982) 154:801-18.

9. Moloney GE, Cowdell RH, Lewis CL. Malignant pheochromocytoma of the bladder. Br J Urol (1966) 38:461-70. doi:10.1111/j.1464-410X.1966.tb09736.x

10. Pham TH, Moir C, Thompson GB, Zarroug AE, Hamner CE, Farley D, et al. Pheochromocytoma and paraganglioma in children: a review of medical and surgical management at a tertiary care center. Pediatrics (2006) 118:1109-17. doi:10.1542/peds.2005-2299

11. Fishbein L, Bonner L, Torigian DA, Nathanson KL, Cohen DL, Pryma D, et al. External beam radiation therapy (EBRT) for patients with malignant pheochromocytoma and non-head and -neck paraganglioma: combination with 131IMIBG. Horm Metab Res (2012) 44:405-10. doi:10.1055/s-0032- 1308992

12. Yoshida S, Nakagomia K, Goto S, Kobayashi S. Pheochromocytoma of the urinary bladder: effectiveness of radiation therapy in conjunction with chemotherapy. Int J Urol (2004) 11:175-7. doi:10.1111/j.1442-2042.2003.00758.x

13. Elder EE, Hjelm Skog AL, Hoog A, Hamberger B. The management of benign and malignant pheochromocytoma and abdominal paraganglioma. Eur J Surg Oncol (2003) 29:278-83. doi:10.1053/ejso.2002.1413

14. Teno S, Tanabe A, Nomura K, Demura H. Acutely exacerbated hypertension and increased inflammatory signs due to radiation treatment for metastatic pheochromocytoma. Endocrinol J (1996) 43:511-6.

15. Brodkey JA, Brodkey JS, Watridge CB. Metastatic paraganglioma causing spinal cord compression. Spine (1995) 23:367-72. doi:10.1097/00007632-19950200000021 
16. Hamilton MA, Tait D. Metastatic paraganglioma causing spinal cord compression. Br J Radiol (2000) 73:901-4. doi:10.1259/bjr.73.872.11026870

17. Jindel R, Gupta AK, Mahapatra AK, Singhal RM. Extradural paraganglioma with multiple skeletal metastases. Br J Radiol (1992) 65:938-40. doi:10.1259/00071285-65-778-938

18. Yu L, Fleckman AM, Chadha M, Sacks E, Levetan C, Vikram B. Radiation therapy of metastatic pheochromocytoma: case report and review of the literature. Am J Clin Oncol (1996) 19:389-93. doi:10.1097/00000421-199608000-00015

19. Olson JJ, Loftus CM, Hitchon PW. Metastatic pheochromocytoma of the cervical spine. Spine (1989) 14:349-51. doi:10.1097/00007632-198903000-00018

20. Siddiqui MZ, Finn E, Spanos G. High voltage irradiation and combination chemotherapy for malignant pheochromocytoma. Cancer (1988) 62:686-90. doi:10.1002/1097-0142(19880815)62:4<686::AID-CNCR2820620407>3.0. $\mathrm{CO} ; 2-7$

21. James RE, Baker HL, Scanlon PW. The roentgenologic aspects of metastatic pheochromocytoma. Am J Roentgenol Radium Ther Nucl Med (1972) 115:783-93. doi:10.2214/ajr.115.4.783

22. Holsti LR.Malignant extra-adrenal pheochromocytoma. Br J Radiol (1964) 37:944-7. doi:10.1259/0007-1285-37-444-944

23. Hinerman RW, Amdur RJ, Morris CG, Kirwan J, Mendenhall WM. Definitive radiotherapy in the management of paraganglioma arising in the head and neck: a 35-year experience. Head Neck (2008) 30:1431-8. doi:10.1002/ hed. 20885

Conflict of Interest Statement: The authors declare that the research was conducted in the absence of any commercial or financial relationships that could be construed as a potential conflict of interest.

Received: 21 April 2014; accepted: 10 June 2014; published online: 27 June 2014.

Citation: Vogel J, Atanacio AS, Prodanov T, Turkbey BI, Adams K, Martucci V, Camphausen K, Fojo AT, Pacak Kand Kaushal A (2014) External beam radiation therapy in treatment of malignant pheochromocytoma and paraganglioma. Front. Oncol. 4:166. doi: $10.3389 /$ fonc. 2014.00166

This article was submitted to Radiation Oncology, a section of the journal Frontiers in Oncology.

Copyright (C) 2014 Vogel, Atanacio, Prodanov, Turkbey, Adams, Martucci, Camphausen, Fojo, Pacak and Kaushal. This is an open-access article distributed under the terms of the Creative Commons Attribution License (CC BY). The use, distribution or reproduction in other forums is permitted, provided the original author (s) or licensor are credited and that the original publication in this journal is cited, in accordance with accepted academic practice. No use, distribution or reproduction is permitted which does not comply with these terms. 